\title{
CFD investigation of the cold hydrodynamics of a laboratory scale CFB furnace
}

\author{
A.Mercy Vasan, N.Prasanna,M.Vivekanandan,V.Gopalakrishnan \\ Saranathan College of Engineering,Tiruchirapalli,India \\ vasan.mercy@gmail.com \\ Kongu College of Engineering,Perundurai, India \\ vmlnprasanna@gmail.com \\ National Institute of Technology,Tiruchirapalli,India \\ vivekbanu@gmail.com \\ M.A.M.College of Engineering, Tiruchirapalli,India \\ gopalakrishnan.vgk@gmail.com
}

\begin{abstract}
This investigation presents a computational and experimental study of the flow characteristics of a laboratory scale CFB cold model riser. i) The first part of the work deals with 2D, CFD validation of a literature based CFB riser of circular cross section of $1 \mathrm{~m}$ height. Simulation results showed good agreement with experimental literature data for radial profiles of volume fraction and particle velocity. ii) The second part is a work on simulation and experimental verification of a CFB riser flow characteristics of a CFB riser of rectangular cross section (400mm x 550 $\mathrm{mm} \times 2000 \mathrm{~mm})$. An experimental run on the test rig was conducted for sand of 300 micron size at a fluidization velocity of $4 \mathrm{~m} / \mathrm{s}$ and the fluidization behavior was captured on a high speed camera. For simulation, 3D, transient, Euler-ian approach combined with the Kinetic theory of Granular flow and Gidaspow drag model was used to describe the gas-particle behavior. A frame by frame visual comparison of instantaneous volume fraction distribution was made between camera images and 3D simulated profiles. A further graphical comparison between experimental literature data and simulated 3D profiles of volume fraction and particle velocity profiles yielded fairly good results. It was observed that, in spite of non inclusion of turbulence factor in the current 3D simulation, no significant influence was observed in the results
\end{abstract}

\section{Indexing terms/Keywords}

CFB, CFD, simulation, volume fraction, particle velocity

\section{Academic Discipline And Sub-Disciplines}

Mechanical Engineering, Chemical Engineering

\section{SUBJECT CLASSIFICATION}

Heat transfer, Fluid Dynamics, combustion, green technology

\section{TYPE (METHOD/APPROACH)}

CFD(Computational Fluid Dynamics) analysis and experimental investigation

\section{INTRODUCTION}

CFB technology finds applications in most industrial processes like fluid catalytic cracking, coal combustion, pneumatic transport etc. [1]. Boiler applications have been largely benefitted by its characteristic low emissions and fuel flexibility. Amongst many factors, riser hydrodynamics is of chief interest in optimizing CFB reactor design and predicting performance parameters to improve plant efficiency. The riser is characterized by complex, transient multiphase flow and is the subject of continuous research in CFB literature. Gas velocity, solid circulation rate, particle size distribution (PSD), solid volume fraction etc. in risers have been widely studied parameters. The overall pressure difference between the cocurrent riser flow and the con-current down comer flow is another governing factor of interest. Both axial and radial crosssections of the riser show wide poly-dispersity and non-uniformity. Radially, the core-annular flow has been classically established as a consequence of particle segregation, though certain studies also reiterate the presence of a third zone (core-annulus-wall). Axially, poly-dispersity shows itself in terms of a bottom dense zone, a dilute top zone and an acceleration regime in between with vigorous mixing. Clustering is another phenomenon, which has gained recent popularity in hydrodynamic study due to its continuous evolving nature and its strong influence on gas - solid mixing characteristics. Back-mixing effects further add to the complexity of flow study. Early 1-D models were deficient in correctly predicting the flow structure and showed deviation from available measured results. Subsequent $2 \mathrm{D}$ simulations have been useful for qualitatively evaluating fundamental flow studies. However, 3D simulations provide a realistic representation of flow dynamics despite the prohibitive computational cost and time involved. Also, transient simulation is preferred over steady state simulation to effectively capture the instantaneous changes in various parameters. Among the various cross sections of risers, tall, narrow, tubular cross sections are characteristic of FCC applications, while, rectangular or square risers are used to approximate CFB boiler risers. More studies, integrating all these phenomena would produce a more satisfying model, which can be used as a bench mark for riser flow studies. The main objective of this work is to study the solid volume fraction distribution across the cold flow model of a laboratory scale riser and validate the results against experimental data. Of the numerical models available to simulate the two phase flow, the Euler-ianEuler-ian method is chosen for its versatility, better accuracy and computational simplicity. It treats the gas and solid 
phases as continuous, interpenetrating medium, treating the inter-phase and intra-phase relations with suitable closure relations. Though, Lagrang-ian model( single-particle tracking) and hybrid models like MP-PIC and CPFD (parcel based approach) are more advanced and accurate, they fall short in their inability to handle huge particle numbers(of the order of billions) as is the case in real-time boilers and are limited to small scale models due to prohibitive computational time and cost. This investigation consists of two parts i) $2 \mathrm{D}$ validation of a circular cross section CFB riser from literature using CFD results ii) Experimental and simulation studies on a CFBC riser of rectangular cross section and literature comparison.

\section{CFD Validation of literature work:}

The experimental data obtained from CFBC set up of Samuelsberg and Hjertager [2] is popularly used in literature for verifying simulation results. A sketch of the setup is shown in fig.1.

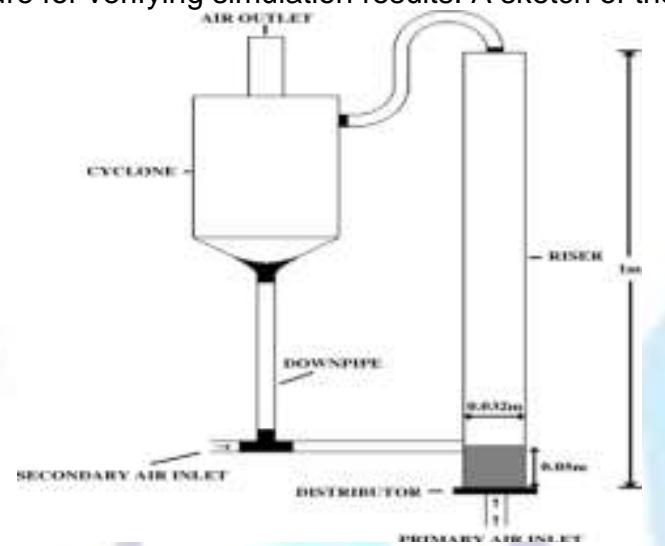

Figure.1.CFB experimental setup of Samuelsberg and Hjertager

The laboratory scale CFBC reactor was a plexi-glass structure of circular cross section $(0.032 \mathrm{~m}$ diameter) and $1.0 \mathrm{~m}$ height with a glass cyclone. Secondary air at $0.05 \mathrm{~m} / \mathrm{s}$ was introduced at $0.05 \mathrm{~m}$ above the fibre plate distributor to recirculate the solids from cyclone to bed. Sand particles of $60 \mu \mathrm{m}$ size and $600 \mathrm{~kg} / \mathrm{m}^{3}$ density were subjected to $0.36,0.71$ and $1.42 \mathrm{~m} / \mathrm{s}$ superficial gas velocity at ambient temperature.LDA measurements yielded radial profiles and root mean square velocity (RMS) of particles at heights $0.16 \mathrm{~m}, 0.32 \mathrm{~m}$ and $0.48 \mathrm{~m}$. The numerical analysis carried out by Samuelsberg et al. was based on the two fluid model(TFM) combined with the Gidaspow drag model and turbulent kinetic energy equation and a numerical CFD model was developed. Spalding's numerical procedure [3] was used to solve mass and momentum partial differential equations. Finite volume method was used to discretize the computational domain. The pressure velocity coupling was handled by the IPSA. Experimental and numerical results showed good agreement for a superficial velocity of $1.42 \mathrm{~m} / \mathrm{s}$. Further validation was carried out on the same experimental set up by Mathiesen et al[4] . He obtained solid volume fraction and velocity profiles for two different solid phases of differing sizes. Good agreement between experimental LDA measurements and computed values was established at all heights except $0.2 \mathrm{~m}$. Following experimental and numerical procedures, 2D, CFD simulation is carried out in this work using FLUENT 6.0 to verify the previous findings. Meshing of the flow region was done using Gambit software and modeled using FLUENT.

Table 1:

PHASE PROPERTIES: AIR

\begin{tabular}{|l|c|}
\hline Primary velocity $[\mathrm{m} / \mathrm{s}]$ & 1.42 \\
\hline Secondary velocity $[\mathrm{m} / \mathrm{s}]$ & 0.05 \\
\hline Density $\left[\mathrm{kg} / \mathrm{m}^{3}\right]$ & 1.225 \\
\hline
\end{tabular}

COAL

\begin{tabular}{|l|c|}
\hline Particle diameter [m] & $70^{*} 10^{-6}$ \\
\hline Particle density & 1654 \\
\hline Particle coeff of restitution & 0.9 \\
\hline Wall coeff of restitution & 0.9 \\
\hline Granular viscosity $[\mathrm{kg} /(\mathrm{ms})]$ & Syamlal-obrien \\
\hline
\end{tabular}

4331 I P a g e 


\begin{tabular}{|l|c|}
\hline $\begin{array}{l}\text { Granular bulk viscosity } \\
{[\mathrm{kg} /(\mathrm{ms})]}\end{array}$ & Lun et al \\
\hline Frictional viscosity $[\mathrm{kg} /(\mathrm{ms})]$ & Schaeffer \\
\hline Angle of internal friction [ $\left.{ }^{\circ}\right]$ & 30 \\
\hline Granular temperatue $\left[\mathrm{m}^{2} / \mathrm{s}^{2}\right]$ & Algebraic \\
\hline Solid pressure $[\mathrm{pa}]$ & Lun et al \\
\hline Radial distribution & Lun et al \\
\hline Elasticity modulus & Derived \\
\hline Packing limit & 0.652 \\
\hline
\end{tabular}

\section{OPERATING AND BOUNDARY CONDITIONS}

\begin{tabular}{|l|c|}
\hline Operating pressure [pa] & 101325 \\
\hline Gravity $\left[\mathrm{m} / \mathrm{s}^{2}\right]$ & $\begin{array}{c}-9.81 \text { in } \mathrm{y} \\
\text { direction }\end{array}$ \\
\hline $\begin{array}{l}\text { Specific operating density } \\
{\left[\mathrm{kg} / \mathrm{m}^{3}\right]}\end{array}$ & 0.328984 \\
\hline $\begin{array}{l}\text { Turbulent kinetic energy } \\
{\left[\mathrm{m}^{2} / \mathrm{s}^{2}\right]}\end{array}$ & 0.005 \\
\hline $\begin{array}{l}\text { Turbulent dissipation rate } \\
{\left[\mathrm{m}^{2} / \mathrm{s}^{3}\right]}\end{array}$ & 5 \\
\hline Primary air velocity $[\mathrm{m} / \mathrm{s}]$ & 1.42 \\
\hline Secondary air velocity [m/s] & 0.05 \\
\hline Coal inlet velocity $[\mathrm{m} / \mathrm{s}]$ & 0.05 \\
\hline
\end{tabular}

Simulation results of radial distribution of volume fraction (Figure.2) showed the classical core annular structure along the riser. The centre showed a dilute region with reduced solids concentration due to high core velocity of lighter particles which get fully circulated along the loop. The migration of heavier solids towards the wall and their down flow presents a higher volume fraction along the wall and a comparatively lower velocity. The same could be observed from experimental data measured in literature. However, a slight over prediction of wall solids concentration could be observed, which could be attributed to the wall boundary conditions chosen. Velocity profiles (Figure 3)also showed a closer agreement with measured data from literature and simulated results by L.M.Armstrong[5].2D and 3D profiles of volume fraction in L.M.Armstrong's work showed very little difference, except that, despite using a coarse mesh for $3 d$ simulation, it took much longer time than 2D simulation.

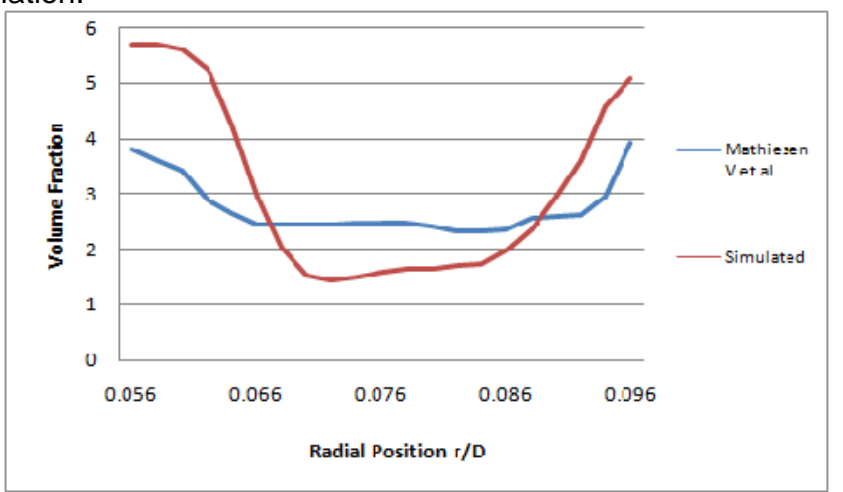

Figure 2. Radial distribution of volume fraction 


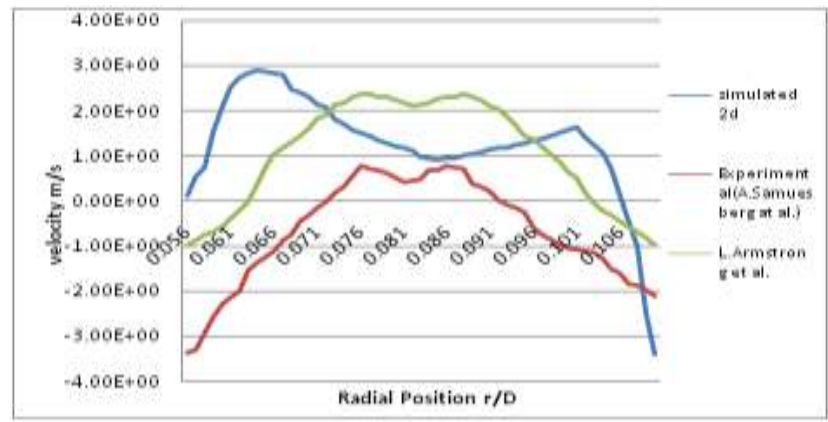

Figure 3. Comparison of experimental and simulated velocity profiles

The above CFD validation encouraged the author to fabricate a scaled down, cold CFB reactor model $2 \mathrm{~m}$ height and of rectangular cross section. With very limited CFB experimental data available and expensive instrumentation required, validation of simulation results is quite challenging. Hence, for validation, the author depends on literature data.

The first part of this work does a quantitative validation of the volume fraction profiles and particle velocity profiles obtained through numerical procedure and CFD simulation.

\section{Current Experimental work:}

The next investigation is on the current experimental CFBC setup, completely made of steel, except one side of the riser column, which is made of Plexi-glass for visualizing the fluidization process. The entire loop consists of i) a fluidizing bed of $600 \mathrm{~mm}$ height with 81 nozzles arranged in $9 \times 9$ array .The plenum chamber is about $200 \mathrm{~mm}$ height. ii)a riser of rectangular cross section of size $400 \mathrm{~mm} \times 500 \mathrm{~mm}$ and $2 \mathrm{~m}$ height iii) an exit duct iv) Cyclone separator v) loop seal for re-injection of re-circulated solids. Figure 4. shows the experimental set-up.
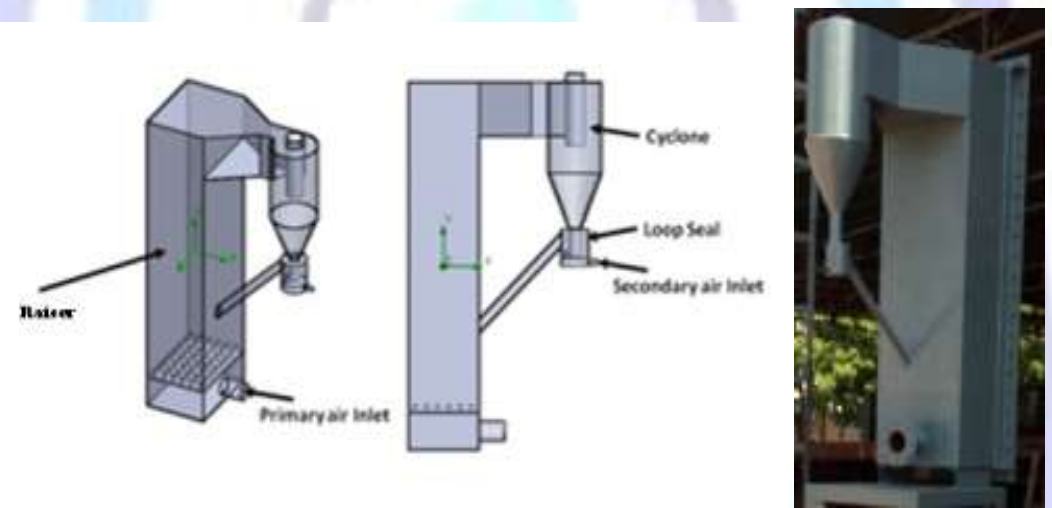

Figure 4. Experimental setup of CFBC

Fuel feed for hot run may be a mixture of coal and sand, but the current paper deals with cold run and sand of 1600 $\mathrm{kg} / \mathrm{m}^{3}$ and 300 microns in size was used. A centrifugal blower was used to provide fluidizing air. Fluidization of sand was carried out at $4 \mathrm{~m} / \mathrm{s}$. Good mixing characteristics were observed through the plexi-glass panel of the riser, showing a dense bottom region and a dilute upper region. The particles thrown out to the exit were captured by the cyclone separator and re-circulated to the bottom bed. The fluidization phenomenon was captured on a camera with a resolution of 12 mega pixels and 100 frames per second. A visual inspection of the volume fraction distribution was made by a frame by frame examination. Table 1 gives particle properties of sand.

Table 2:

Solid Properties

\begin{tabular}{ll}
\hline Property & Value \\
\hline Density & $1600 \mathrm{~kg} / \mathrm{m}^{3}$ \\
\hline Diameter & 300 microns \\
\hline Granular Viscosity & Gidaspow model in fluent \\
\hline Frictional Viscosity & Schaeffer model in fluent \\
\hline
\end{tabular}

\section{CFD model description:}

\subsection{Governing Equations:}


This work employs the Eulerian-Eulerian approach, also called Two Fluid Method (TFM) which treats both phases(gas and solid) as continuous, interpenetrating media. Despite the advantages of Lagrangian method, this method is found more suitable for large industrial flows in dealing with big geometries due to the lesser computational time and cost.

The continuity equation for a generic phase $\mathrm{q}$ and the momentum equations for gas $\mathrm{g}$ and solids $\mathrm{s}$ can be written as follows:

$$
\begin{aligned}
& \frac{\partial}{\partial t}\left(\alpha_{q} \rho_{q}\right)+\nabla \cdot\left(\alpha_{q} \rho_{q} v_{q}\right)=0 \\
& \frac{\partial}{\partial t}\left(\alpha_{g} \rho_{g} v_{g}\right)+\nabla \cdot\left(\alpha_{g} \rho_{g} v_{g} v_{g}\right)=-\alpha_{g} \nabla p+\nabla \cdot \tau_{g}+\alpha_{g} \rho_{g} g+\beta\left(v_{s-} v_{g}\right) \\
& \frac{\partial}{\partial t}\left(\alpha_{s} \rho_{s} v_{s}\right)+\nabla \cdot\left(\alpha_{s} \rho_{s} v_{s} v_{g s}\right)=-\alpha_{s} \nabla p-\nabla \mathrm{p}_{s}+\nabla \cdot \tau_{s}+\alpha_{s} \rho_{s} g+\beta\left(v_{g-} v_{s}\right)
\end{aligned}
$$

where $\alpha_{\mathrm{q}}$ is the volume fraction and $\mathbf{v}_{\mathrm{q}}$ the velocity of phase $\mathrm{q}, \mathrm{p}$ the gas phase pressure, $\mathrm{p}_{\mathrm{s}}$ the solid phase pressure, $\beta$ the inter-phase drag coefficient and $\rho_{g}$ and $\rho_{S}$ are the gas and solid densities. KTGF [6, 7] is used to describe particle rheology in terms of granular temperature resulting from particle collisions and is represented by

$$
\Theta_{\mathrm{S}}=\frac{1}{3}\left\langle c^{2}\right\rangle
$$

where $\mathrm{c}$ is the fluctuation velocity of the solid particle and the brackets represent ensemble averaging. The particle phase viscosities and pressure are functions of this temperature and in addition to the equations of motion, a transport equation is solved for the granular temperature. The solid pressure term which accounts for additional normal stresses are adapted from the Lun et al. version

where

$$
p_{S}=\alpha_{S} \rho_{S} \Theta_{S}+2 \rho_{S}\left(1+e_{S}\right) \alpha_{s}^{2} g_{0} \Theta_{S}
$$

$$
g_{o}=\frac{1}{1-\sqrt[3]{\left(\frac{\alpha_{s}}{\alpha_{s} \max }\right)}} \text { and }
$$

$\mathrm{e}_{\mathrm{S}}$ is taken to be nearly 1 for typical particles.

The Schaffer model [8] was chosen to account for frictional viscosity of particles.

\subsection{Drag model:}

The inter-phase momentum exchange which is accounted for, by the drag models is crucial in accurately describing the hydrodynamics of multiphase flow. Literature, reports of a range of drag models from the earliest Ergun model to the recent, much improved cluster structure dependent (CSD) drag models. In this work, the Gidaspow drag model[9], which is a combination of Ergun [10]and Wen-Yu[11] models, is employed.

The inter-phase momentum exchange coefficient is given by

$$
\begin{gathered}
K_{s g}=\frac{3 \rho_{g} \alpha_{g}\left(1-\alpha_{g}\right)}{4 d_{p}} C_{D}\left|\overrightarrow{u_{s}}-\overrightarrow{u_{g}}\right| \alpha_{g}{ }^{-2.65} \quad \text { for } \quad \alpha_{g}>0.8 \text { (Ergun) } \\
\text { and } \\
K_{s g}=150 \frac{\mu_{g\left(1-\alpha_{g}\right)^{2}}}{\alpha_{g}\left(d_{s} \varnothing\right)^{2}}+1.75 \frac{\rho_{g}\left(\left|\overrightarrow{u_{s}}-\overrightarrow{u_{g}}\right|\right)\left(1-\alpha_{g}\right)}{\left(1-\alpha_{g}\right)} \quad \text { for } \quad \alpha_{g}<0.8 \quad \text { (Wen-Yu) }
\end{gathered}
$$

\section{Simulation procedure:}

\subsection{Modeling and simulation software:}

ANSYS Fluent Inc., Version 16.0, a commercial CFD package, was used to numerically solve the governing equations. Finite volume method [12]was employed for discretization of grids. Pressure -Velocity coupling was solved by SIMPLE algorithm. A convergence criterion of 0.0001 was chosen to account for error between successive iterations. Modeling and Meshing of the experimental model were done with Solid Works modeling software on a domain of 85206 nodes and 456894 elements for the entire CFB loop. Simulation was carried out for 1.4 seconds. 


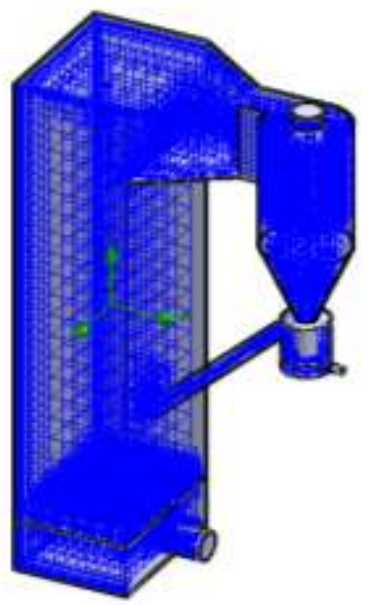

Figure 5. Meshed model of the experimental setup

Along the riser height more uniform grid spacing was employed. Non-uniform grid spacing along the cross sectional widths were used, with more cells near the wall and corners to capture the wall phenomenon. Figure.5 shows the meshed structure of the CFB setup. Modeling parameters chosen for simulating flow patterns are given below.

Table 3

Boundary Conditions and Modeling Parameters

\begin{tabular}{ll}
\multicolumn{2}{c}{ Table 3 } \\
\multicolumn{1}{c}{ Boundary Conditions and Modeling Parameters } \\
\hline Property & Value \\
\hline Gas Density & $1.225 \mathrm{~kg} / \mathrm{m}^{3}$ \\
\hline Inlet gas Velocity & $4 \mathrm{~m} / \mathrm{s}$ \\
\hline Bed Height & $1 \mathrm{~m}$ \\
\hline Bed Size & $0.4 \times 0.55 \mathrm{~m}$ \\
\hline Solid and Air Inlet & Velocity inlet \\
\hline Outlet & Pressure Outlet \\
\hline Wall Boundary Conditions & No slip for gas and \\
\hline & partial slip for \\
\hline & particles \\
\hline Specularity coefficient & 0.6 \\
\hline Restitution Coefficient & 0.9 \\
\hline Time Step & $0.001 \mathrm{~s}$ \\
\hline Convergence Criteria & 0.0001 \\
\hline
\end{tabular}

\subsection{Simulation conditions:}

Velocity inlet was employed as inlet condition for air and gas flow and outlet condition was taken as pressure outlet. The effect of the opening ratio of distributor plate was neglected. Wall condition was based on Johnson-Jackson boundary condition [13]. Accordingly, no slip condition was used for gas and partial slip condition for particles. Transient simulations were performed for 5 seconds for a time step of $0.001 \mathrm{~s}$ on the imported model using FLUENT. Specularity coefficient of the particle was chosen as 0.6 and restitution coefficient as 0.9 .

\section{Results and discussion:}

\subsection{Model Validation against experimental results}

\subsubsection{Solid volume fraction:}

The hydrodynamic behavior of fluidized sand, at a velocity of $4 \mathrm{~m} / \mathrm{s}$ was captured on a high resolution camera at 100 frames per second. A visual comparison of the solid volume fraction distribution and simulation results showed close agreement. The initial effect of distributor holes and the gradual onset of fluidization could be visualized both in the experimental setup and simulation result. Volume fraction was found to exhibit a similar trend at various riser heights and instants of time. Eight frozen frames of images on the high speed camera and corresponding simulation images at various 
instants of time have been compared as shown in Figure 6(a) to (h). The dense bottom region with more solids concentration and included voids and the diluted upper region of the riser could be visualized.
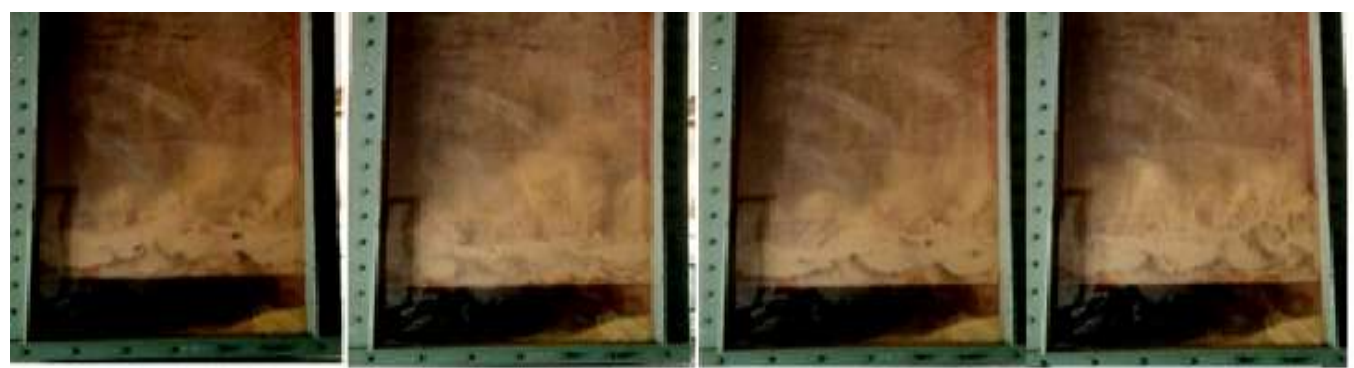
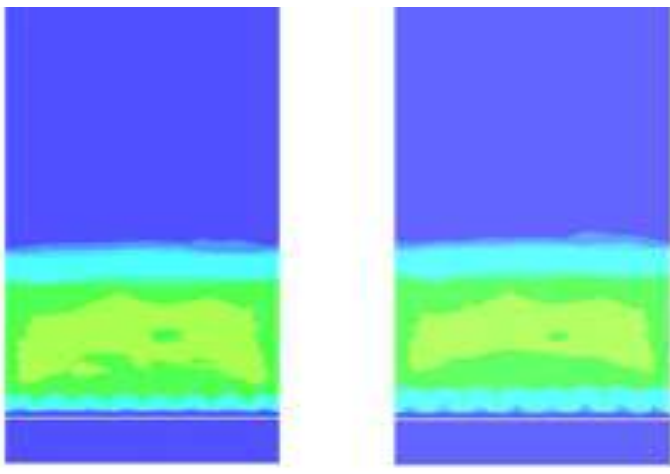

Figure 6(b)
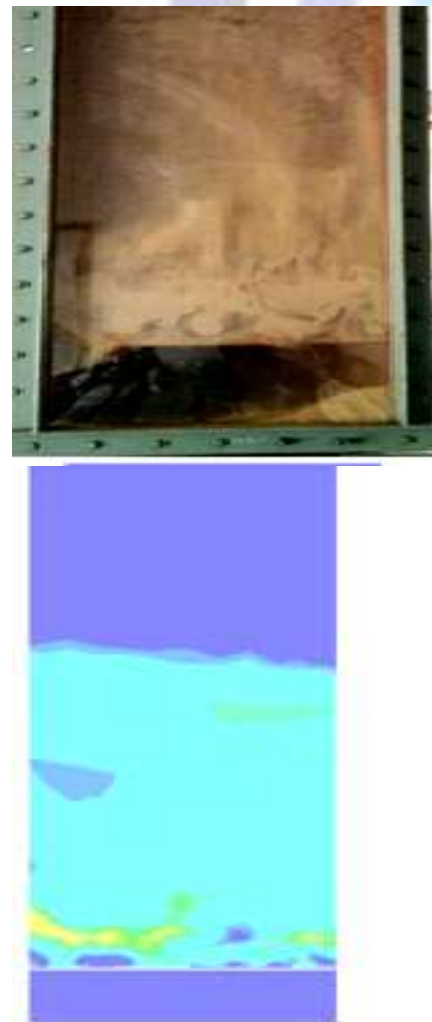

Figure 6(e)
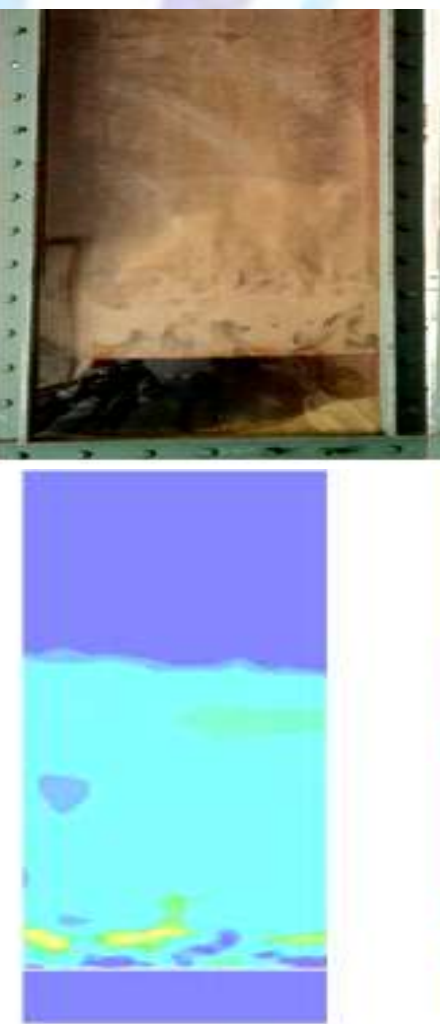

Figure 6(f)

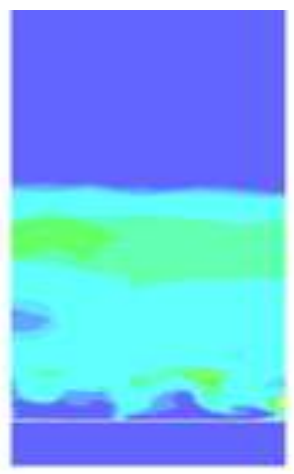

Figure 6(c)
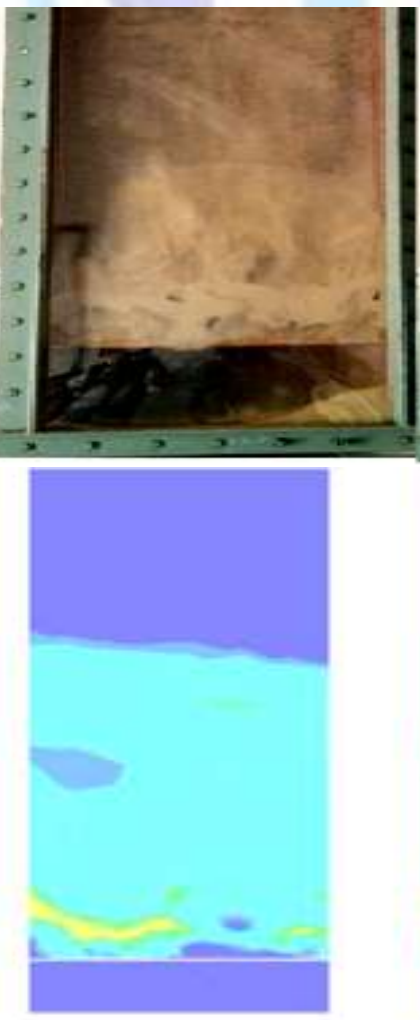

Figure 6(g)

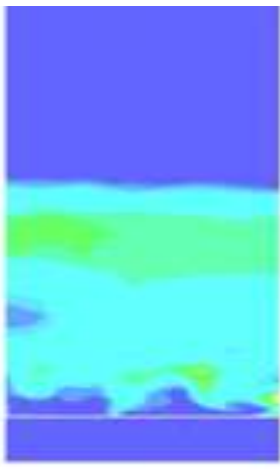

Figure 6(d)
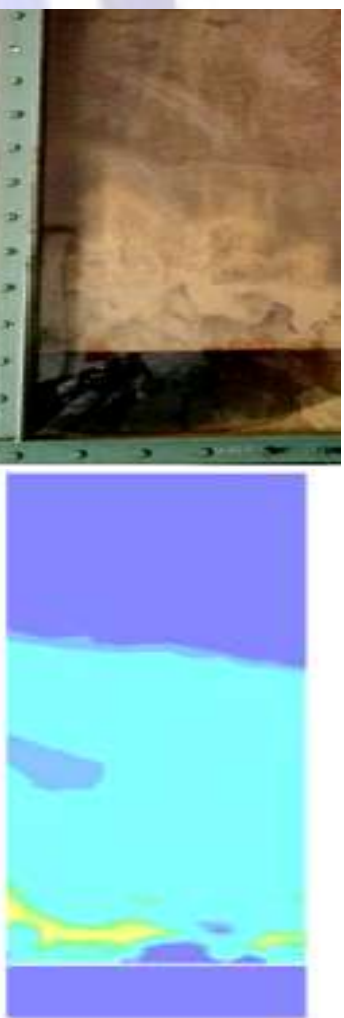

Figure 6(h) 

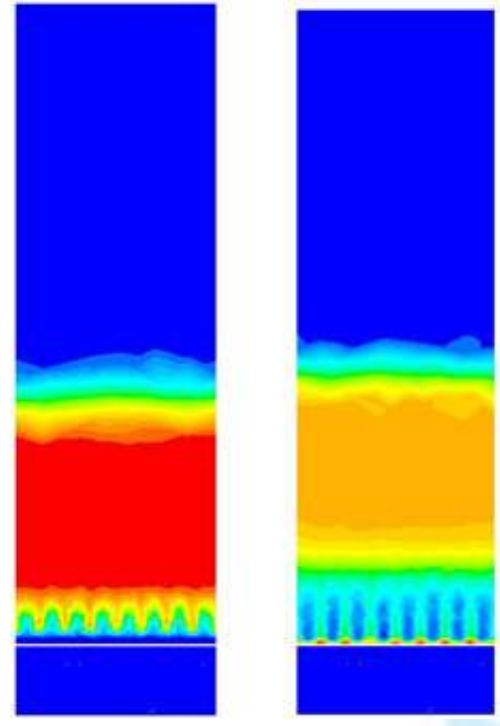

$0.1 \mathrm{~s}$

$0.2 \mathrm{~s}$

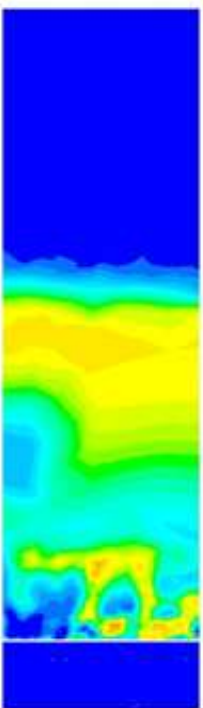

$0.5 \mathrm{~s}$

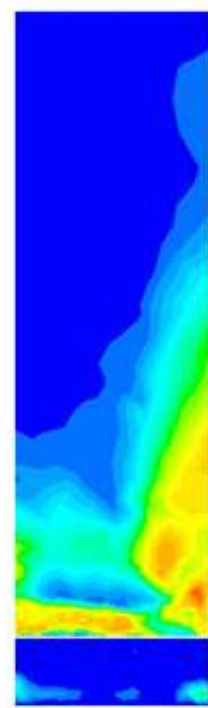

1s
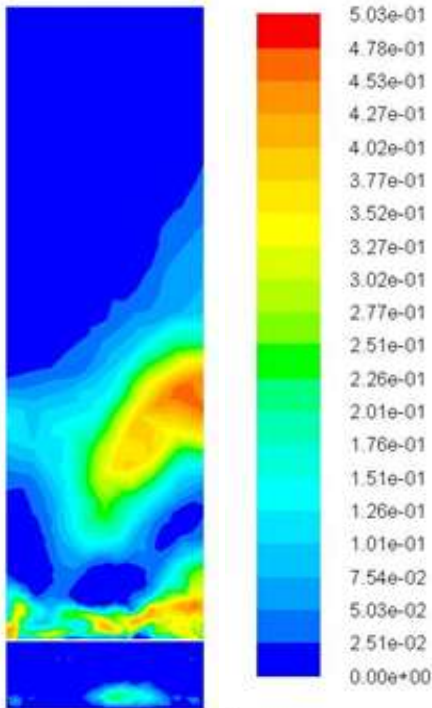

$1.4 \mathrm{~s}$

Fig: 7(a) The radial distributions of computed time-averaged solid volume fraction at five different time instants

The transient simulation was run for $1.4 \mathrm{~s}$ which shows continuous change of volume fraction (Fig.8.a). The effect of recirculation could be observed at the bottom of the riser. The strong yellow strands show increased volume fraction at the bottom right due to additional volume of solids getting re-circulated from the loop seal. The effect of air penetration through distributor holes at the beginning of fluidization could be observed at $0.1 \mathrm{~s}$ and $0.2 \mathrm{~s}$. The steady increase in axial solids distribution and throw-up of solids along the riser height with successive time instants.

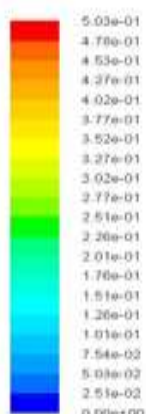

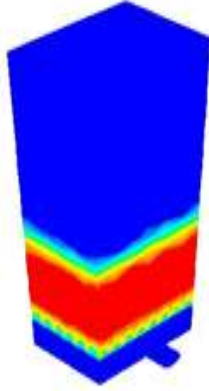

0.15

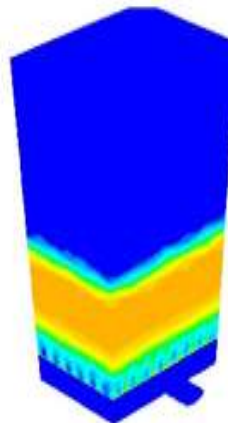

0.28

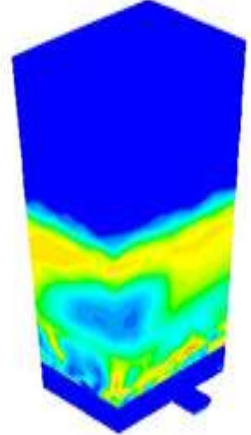

$0.5 s$

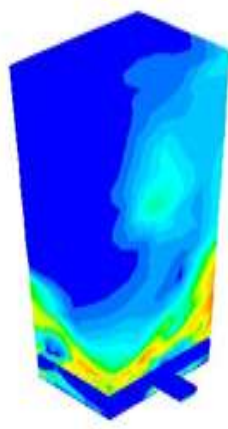

$1 \mathrm{~s}$

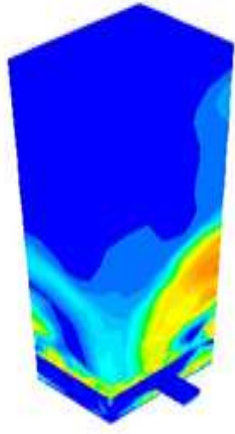

$1.4 \mathrm{~s}$

Figure 7(b) 3D view of wall concentration of solids at five different time instants

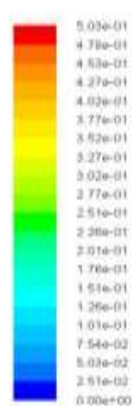

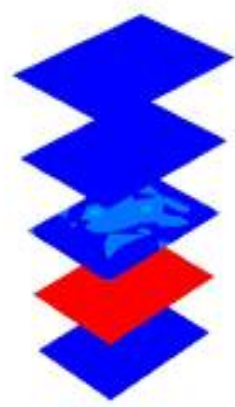

$0.1 \mathrm{~s}$

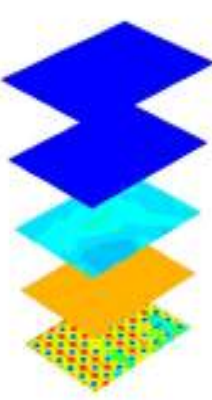

$0.2 \mathrm{~s}$

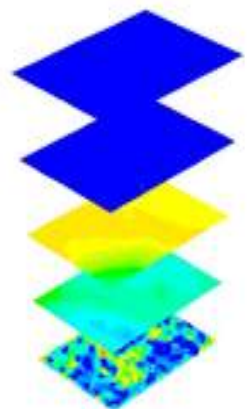

$0.5 \mathrm{~s}$

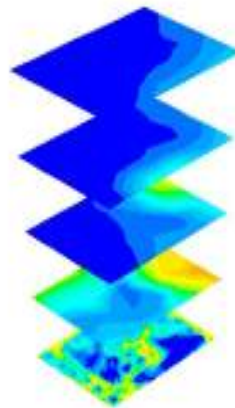

$1 \mathrm{~s}$

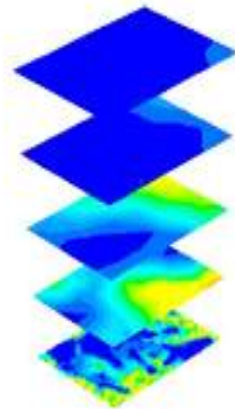

$1.4 \mathrm{~s}$

Figure 7(c) The radial distributions of computed time-averaged solid volume fraction at five different planes 


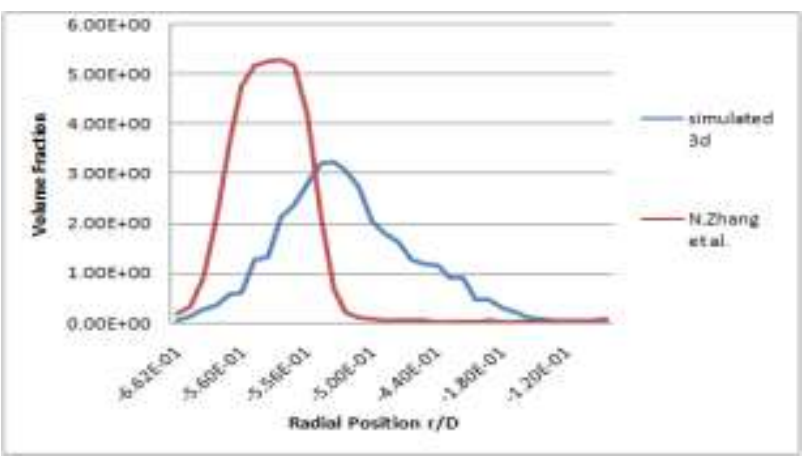

Figure. 8 Radial distribution of volume fraction

Figure.7 (a) and (b) show the concentration of solids towards the wall at five different instants of time, as fluidization progresses. The streaming of air through distributor holes and the lift of sand particles at the beginning of fluidization can be seen at $0.1 \mathrm{~s}$ and $0.2 \mathrm{~s}$. Polarization of denser solids towards the wall and formation of a dilute core can be observed at 0.5s. Figure.7(c) shows a fully developed flow structure with nearly constant volume fraction with increase in riser height. Graphical distribution of the same is shown in Figure 8.Comparison between experimental and simulation results show close agreement up to $0.5 \mathrm{~m}$, though slight over prediction of values is observed at greater heights. Simulation results of solid volume fraction profile towards the end of 1.4 seconds shows a slightly different trend with more solids being thrown upwards towards the right wall. This is attributed to the flow of lighter particles towards the exit duct for recirculation. 3D CFD simulations carried out on a 150 MW CFBC boiler with two cyclone separators by Zhang et al.[14] revealed similar volume fraction profiles at $5 \mathrm{~m}$ height. Initially, up to $0.2 \mathrm{~s}$ the region covering $0.5 \mathrm{~m}$ height from the bottom is largely influenced by the flow through distributor holes, showing an unpredictable trend. There is particle congestion and clustering with particles occupying the entire cross sectional area. Beyond $0.2 \mathrm{~s}$, a parabolic trend can be observed with a peak at the centre and a valley along the wall. Acceleration of particles at subsequent time instants leads to a more uniform profile at the top of the riser indicative of fines migration towards the exit duct.

\subsubsection{Velocity distribution:}

The inlet gas velocity is found to have a significant effect on the particle hydrodynamics. Axially, the particle velocity is found to increase. The $x$-averaged particle velocity shows a positive value on one side and a negative value on the other side of the riser. The negative velocity indicates the flow towards the left side in the $x$-direction and positive velocity indicates flow towards the right side in the $\mathrm{x}$-direction. This shows net migration of solid particles towards the wall region in the riser. Velocity fluctuations are observed to be large in the direction of the flow. Thus, the effect of axial velocity is more pronounced than the radial velocity distribution. Hence, the axial solid velocity has a much more significant effect than radial solid velocity because the axial direction is the main flow direction. Validation of 3D velocity profiles is done by comparison with literature experimental and 3D simulated data. Results show good agreement between the three, establishing a predictive trend[Figure.9]. The particle velocity shows a peak along the axis and a dip along the walls. High velocity flows reduce the gas particle drag and increase the suspension tendency of particles giving good mixing characteristics. Low velocity flows increase particle agglomeration and solid downfall along the walls. Solid flux in the entire loop also depends on the axial velocity characteristics.

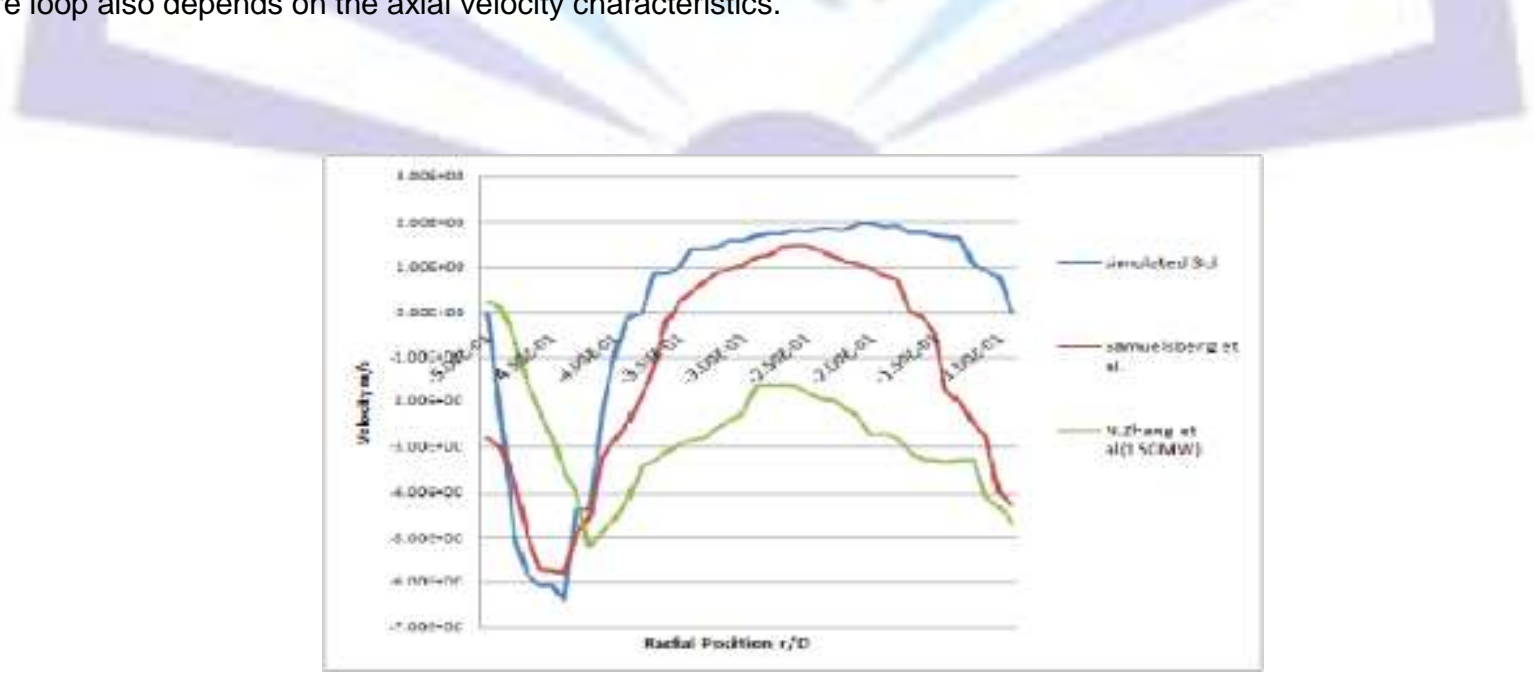

Figure.9 Experimental and computational verification of $3 \mathrm{~d}$ simulation results of particle velocity

The above results agree well with the optical fibre measurements of solids volume and axial velocity profile from literature [15]. 


\section{Conclusion:}

i) The 2D CFD simulation results for volume fraction and particle velocity were obtained using FLUENT software and validated against experimental data for a literature based experimental CFBC setup. The $1 \mathrm{~m}$ height circular cross section riser exhibited similar characteristics computationally and experimentally.

ii) Hydrodynamics of a cold model laboratory scale CFBC riser of $2 \mathrm{~m}$ height was studied in terms of solid volume fraction, axial velocity .Both experimental and CFD simulation results were compared for a fluidization velocity of $4 \mathrm{~m} / \mathrm{s}$. Transient simulation was carried out for1.4 seconds. The conventional TFM combined with Gidaspow drag model was used for simulating the riser hydrodynamics. The fluidizing behaviors of sand at different heights of the riser were captured using a high resolution camera and a visual comparison of solid volume fraction at 8 time instants were made against simulation results. Results pointed out to a similar trend in both cases up to $0.5 \mathrm{~m}$. Under- prediction of solid volume fraction was observed for greater heights Also, the role of axial solid velocity on the non-uniform radial distribution of solids was established.

iii) A significant observation was that laminar treatment of the flow did not have an influence on the results. Inclusion of turbulent models often increase the computational time. It could be conveniently accepted that turbulence models can be ignored for simulating complicated and larger geometries where computational time is large.

iv) Except for corner and wall effects in square shaped risers, hydrodynamic profiles of the circular and square risers generally show a similar trend for solid volume fraction and velocity.

v) Despite the accuracy and clarity of 3D simulations, they require larger computational time. Hence, it is also found that 2D simulations suffice to have clear understanding of the riser dynamics at lesser computing time. However, corner and wall effects are better represented by $3 \mathrm{D}$ simulations for a square riser.

\section{Nomenclature}

$\begin{array}{ll}\text { CFD } & \text { Computational Fluid Dynamics } \\ \text { CFBC } & \text { Circulating Fluidized Bed Combustor } \\ \text { KTGF } & \text { Kinetic Theory of Granular Flow } \\ e_{S} & \text { particle restitution coefficient } \\ \text { go } & \text { radial distribution function } \\ \alpha_{S \max } & \text { Maximum volume fraction of solid phase } \\ d_{p} & \text { particle diameter } \\ C_{D} & \text { drag coefficient } \\ \left|\overrightarrow{u_{s}}-\overrightarrow{u_{g}}\right| & \text { absolute relative interracial velocity of particles compared to fluid }\end{array}$

\section{REFERENCES}

I. Grace, JR., Bi, H.T., Golriz, M.,in: Wen-Ching Yang (Ed.),2003, Circulating fluidized beds, in handbook of fluidization and fluid-particle systems, Marcel Dekker Inc., New York, pp. 485-531.

II. Samuelsberg, Hjertager, BH., Computational modeling of gas-particle flow in a riser, AIChE J. 42 (1996) 1536-1546.

III. Spalding, D.B., 1983, Developments in the IPSA procedure for numerical computation of multiphase-Flow phenomena with interphase slip, unequal temperatures, etc. In: Numerical Properties and Methodologies in Heat Transfer. Hemisphere, Washington DC, pp. 421-476.

IV. Mathiesen,V., Solberg,T., Hjertager, B.H.,2000, An experimental and computational study of multiphase flow behavior in a circulating fluidized bed, International Journal of Multiphase Flow, Vol. 26 , 387-419.

V. Armstrong, L.M., Luo, Gu, S.,2010, Two-dimensional and three-dimensional computational studies of hydrodynamics in the transition from bubbling to circulating fluidised bed, Chemical Engineering Journal ,Vol.160 ,pp $239-248$.

VI. Gidaspow, D., Bezburuah, R., Ding, J.,1992, Hydrodynamics of circulating fluidized beds, kinetic theory approach, Fluidization VII, Proceedings of the 7th Engineering Foundation Conference on Fluidization, pp. 75-82.

VII. Ding, J. , Gidaspow,1990, D.A. Bubbling fluidization model using kinetic theory of granular flow, AIChE J. 36 (4) $523-538$.

VIII. Schaeffer, D. G.,1987, Instability in the evolution equations describing incompressible granular flow. Journal of

4339 | P a g e 
Differential Equations, Volume 6(1), pages 19 - 50. ISSN 0022-0396. doi:10.1016/0022-0396(87)90038-6.

IX. Gidaspow, D., 1994, Multiphase Flow and Fluidization - Continuum and Kinetic Theory Descriptions. Academic Press, ISBN 0-12-282470-9.

X. Ergun, S., 1952, "Fluid Flow Through Packed Columns," Chem. Eng. Prog., Vol.48, pp. 245.

XI. Wen, Y. C., and Y. H. Yu, 1966, "Mechanics of Fluidization,” Chem. Eng.Prog. Symp. Ser., Vol.62, pp.100.

XII.Suhas V.Patankar, 1980, Numerical heat transfer and fluid flow, CRC Press.

XIII P. Johnson, R. Jackson, Frictional-collisional constitutive relations for granular materials, with application to plane shearing, J.Fluid Mech. 176 (1987)67-93.

XIV. Zhang N, Lu B, Wang W, Li J.,2010, "3D CFD simulation of hydrodynamics of a 150 MW circulating fluidized bed boiler", Chem.Eng J., Vol.162, pp.821-828.

XV. Wang C., Zhu J., Li C.,Bargh S., 2014,"Detailed measurements of particle velocity and solids flux in a high density circulating fluidized bed riser", Chemical Engineering Science, Vol.114, pp.9-20.

\section{Author's biography with Photo}

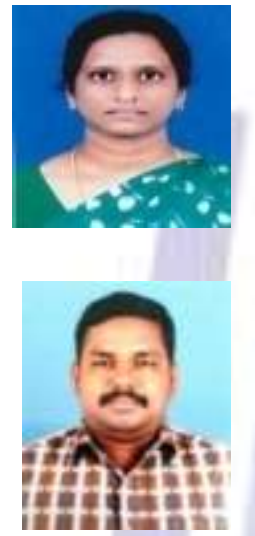

A.Mercy Vasan works as Assistant Professor at Saranathan College of Engineering,Tiruchirapalli,India in the Department of Mechanical Engineering. She holds an undergraduate degree in Mechanical Engineering and a masters degree in Thermal Plant Engineering. She is pursuing her Ph.D in CFD investigation of Circulating Fluidized bed furnaces.

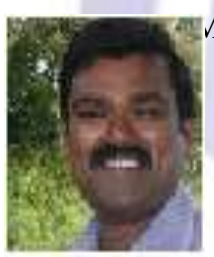

M. Mr.M.Vivekanandan holds a masters degree in CAD/CAM and is currently pursuing Ph.D at National Institute of Technology, Trichy. His work experience involves boiler design, energy auditing and renewable energy systems.His research area is CFD analysis of Circulating fluidized bed boilers.

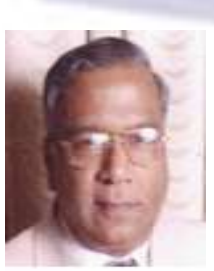

Dr. V.Gopalakrishnan worked as Executive Director ,BHEL,Trichy and holds a Ph.D in coal classification.He is adjunct faculty at IIT,Madras and plays an advisory role in top institutions and organizations.His corporate and teaching experience span over 40 years. 